\title{
PENGARUH PENGGUNAAN STRATEGI GIVING QUESTION AND GETTING ANSWER PADA PEMBELAJARAN DARING BIOLOGI VIA WHATSAPP
}

\author{
Linda Yanti ${ }^{1}$, Dian Nurhofifah ${ }^{1}$ \\ ${ }^{1}$ IAIN Syekh Nurjati Cirebon, Jl. Perjuangan, Sunyaragi, Kec. Kesambi, Kota \\ Cirebon 45132, Jawa Barat, Indonesia \\ E-mail: lindayanti556@gmail.com
}

\begin{abstract}
The strategy of using Giving Question and Getting Answer via Whatsapp need analysist of the relation in biology learning. The purpose of this study to determine whether there is influence of Whatsapp of the strategy Giving Question and Getting Answers to biology online learning through Whatsapp. This research method uses a qualitative descriptive method. Data collection techniques using observation, interviews, and documentation. This study result indicated that learning that dares to use the Whatsapp application with a strategy of Providing Answers and Getting Questions can provide more fun learning so as to increase student enthusiasm and activity. The conclusions obtained from this study use a strategy of Asking Questions and Getting Answers that affect biology online learning through Whatsapp and can be an alternative in online biology learning through Whatsapp in conditions that do not support learning face-to-face learning.
\end{abstract}

Keywords: Giving Question and Getting Answer, Whatsapp, Online learning

\begin{abstract}
Abstrak : Penggunaan strategi Giving Question and Getting Answer via Whatsapp perlu dikaji terkait pengaruhnya dalam pembelajaran biologi. Penelitian ini bertujuan untuk mengetahui ada tidaknya pengaruh penggunaan strategi Giving Question and Getting Answer pada pembelajaran daring biologi via Whatsapp. Metode penelitian ini menggunakan metode deskriptif kualitatif. Data pada penelitian ini dikumpulkan melalui observasi, wawancara, dan dokumentasi. Hasil yang diperoleh menunjukkan bahwa Pembelajaran daring menggunakan aplikasi Whatsapp dengan strategi Giving Question and Getting Answer dapat memberikan pembelajaran yang lebih menyenangkan sehingga meningkatkan antusias dan keaktifan siswa. Kesimpulan yang diperoleh dari penelitian ini yaitu penggunaan strategi Giving Question and Getting Answer berpengaruh terhadap pembelajaran daring biologi via Whatsapp dan bisa menjadi alternatif dalam pembelajaran daring biologi via Whatsapp pada kondisi yang tidak memungkinkan untuk dilakukannya pembelajaran tatap muka.
\end{abstract}

Kata kunci: Giving Question and Getting Answer, Whatsapp, Pembelajaran daring

Media sosial sudah menjadi bagian hidup dari masyarakat di dunia, khususnya di Indonesia. Penggunaan media sosial makin hari makin meningkat karena perkembangan dan inovasi digital saat ini. Media sosial menjadi salah satu kebutuhan pokok digital masyarakat di Indonesia. Penggunaan media sosial saat ini selain sebagai media komunikasi dan informasi juga mengalami proses peralihan sebagai media pembelajaran daring. Pembelajaran daring diharapkan mampu mengatasi proses belajar mengajar tetap berjalan dengan baik meskipun pada kondisi yang tidak memungkinkan untuk dilakukannya pembelajaran tatap muka seperti biasa, seperti pada masa pendemi COVID-19.

Pembelajaran daring bertujuan untuk memenuhi standar pendidikan dengan pemanfaatan teknologi informasi dengan menggunakan perangkat komputer atau gawai yang 
saling terhubung antara siswa dan guru mupun mahasiswa dengan dosen (Avana, 2018). Ada beberapa media sosial yang dapat dimanfaatkan sebagai pembelajaran daring, salah satunya adalah Whatsapp. Pembelajaran daring dengan Whatsapp memanfaatkan fitur chat grup sebagai media kegiatan diskusi. Whatsapp juga memiliki berbagai fitur lain, di antaranya adalah berbagi foto, video, dokumen, dan fitur voice note.

Pembelajaran daring biologi via Whatsapp dirasa tidak cukup jika hanya mengandalkan kegiatan diskusi tanpa menerapkan strategi pembelajaran. Penelitian yang dilakukan oleh Suryadi dalam Sahidillah, dkk (2019) menjelaskan bahwa Whatsapp mempengaruhi disiplin belajar siswa, sehingga aktivitas belajar siswa menurun dan lemah dalam mengikuti pembelajaran. Selain itu, telah umum diketahui bahwa pelajaran biologi dianggap sulit oleh siswa, sehingga guru dituntut harus kreatif dalam mengembangkan materi yang akan diajarkan melalui pembelajaran daring menggunakan Whatsapp dengan strategi tertentu agar hasil belajar siswa meningkat.

Peningkatan hasil belajar siswa dapat diperoleh melalui pembelajaran yang efektif dan menyenangkan. Pembelajaran menurut Warsita (2008: 85) adalah suatu upaya agar siswa belajar atau suatu kegiatan untuk membelajarkan siswa. Dengan kata lain pembelajaran merupakan usaha untuk mengkondisikan siswa untuk belajar. Sementara pengertian pembelajaran yang efektif yang diungkapkan oleh Dick \& Reiser (1989) dalam Warsita (2008: 288) adalah suatu pembelajaran yang memungkinkan siswa untuk belajar ketrampilan spesifik, ilmu pengetahuan, dan sikap serta yang membuat siswa senang. Agar tercapai kegiatan pembelajaran yang efektif dan menyenangkan pemilihan strategi pembelajaran sangat berperan dalam hal ini.

Pada penelitian ini, pembelajaran daring dilakukan dengan strategi Giving Question and Getting Answer yang merupakan salah satu dari tipe model pembelajaran kooperatif yang merangsang peserta didik untuk aktif di dalam kelas serta mendengarkan semua penjelasan guru. Menurut Nengsi dan Oktaria (2019) strategi Giving Question and Getting Answer memungkinkan siswa untuk mengemukakan pikirannya, merangsang siswa agar terlibat dalam interaksi, dan memotivasi siswa agar lebih aktif dalam kegiatan pembelajaran. Sehingga guru dapat menerapkan strategi Giving Question and Getting Answer pada pembelajaran daring biologi via Whatsapp sebagai salah satu upaya terlaksananya pembelajaran yang efektif.

Model pembelajaran GQGA (Giving Question and Getting Answer), siswa didorong untuk bisa mengajukan pertanyaan yang produktif, sebab pertanyaan ini akan mendorong siswa untuk mandiri dan mengembangkan keterampilan ilmiahnya dan implementasinya. 
Siswa juga diharapkan secara aktif dan berani dalam mengemukakan pendapat. Tingkah laku siswa yang dihasilkan dari proses belajar melalui model ini yaitu meliputi pengetahuan, sikap, keterampilan, dan informasi yang baik akan mempengaruhi hasil belajar secara maksimal (Chasanah, dkk., 2012).

Namun demikian, penelitian mengenai pembelajaran daring biologi via Whatsapp dengan penggunaan strategi Giving Question and Getting Answer masih jarang dilakukan. Penggunaan strategi Giving Question and Getting Answer via Whatsapp perlu dikaji terkait pengaruhnya dalam pembelajaran biologi. Oleh karena itu, tujuan dari penelitian ini adalah untuk mengetahui pengaruh penggunaan strategi Giving Question and Getting Answer pada pembelajaran daring biologi via Whatsapp. Hasil penelitian ini diharapkan bisa menjadi alternatif dalam pembelajaran daring biologi via Whatsapp pada kondisi yang tidak memungkinkan untuk dilakukannya pembelajaran tatap muka.

\section{METODE}

Metode yang dilakukan pada penelitian ini yaitu menggunakan metode deskriptif kualitatif. Subjek penelitian ini adalah kelas Biologi 6E Microteaching IAIN Syekh Nurjati untuk jenjang SMA yang berjumlah 18 orang mahasiswa. Dari 18 orang mahasiswa 1 mahasiswa berperan sebagai guru dan sisasnya berperan sebagai murid. Pembelajaran dilakukan dengan menggunakan Whatsapp messenger penerapan strategi pebelajaran Giving Question and Getting Answer dan sisanya berperan sebagai siswa. Teknik pengumpulan data yang digunakan pada penelitian ini yaitu dengan observasi, wawancara, dan dokumentasi.

\section{HASIL}

Hasil observasi dan wawancara yang telah dilakukan di kelas Microteaching Biologi 6E diketahui bahwa Pembelajaran Daring mengunakan Whatsapp serta dengan menerapkan strategi Giving Question and Getting Answer siswa terlihat antusias dan berperan aktif mengikuti pelajaran sesuai dengan intruksi yang diberikan guru. Antusias siswa dapat dilihat saat guru memberikan kesempatan kepada siswa untuk bertanya, delapan dari sembilan siswa yang berada di kelompok Question mengajukan pertanyaan begitu juga saat guru memberikan kesempatan kepada siswa yang berada di kelompok Answer yang ingin menjawab pertanyaan yang diajukan oleh temannya.

Selain itu keaktifan siswa juga dapat dilihat dari banyaknya pesan yang masuk grup Whatsapp secara bersamaan ketika pembelajaran berlangsung untuk mengajukan pertanyaan lebih dulu begitupun juga saat menjawab pertanyaan yang diajukan temannya. Dilihat dari antusias dan keaktifan siswa mengikuti pembelajaran daring dapat diketahui adanya pengaruh 
dari penggunaan strategi pembelajaran Giving Question and Getting Answer. Terdapat perbedaan sebelum dan sesudah penggunaan strategi Giving Question and Getting Answer. Sebelum penggunaan strategi Giving Question and Getting Answer pembelajaran yang dilakukan cenderung monoton karena guru lebih banyak memberikan materi pembelajaran yang khawatir tidak dipahami oleh siswa sedangkan sesudah penggunaan strategi Giving Question and Getting Answer pembelajaran yang dilakukan lebih menyenangkan dan siswa menjadi antusias terhadap pembelajaran daring yang dilakukan.

\section{PEMBAHASAN}

Pembelajaran Daring saat ini sedang banyak dilakukan oleh siswa dan guru yang dikarenkan kondisi yang tidak memungkinkan untuk melakukan pembelajaran dengan tatap muka. Pembelajaran Daring merupakan sebagai cara alternatif agar pembelajaran siswa dikelas agar tetap berjalan dengan baik. Salah satunya dengan menggunkan bantuan aplikasi pembelajaran seperti aplikasi Google Classroom, Edmodo, Google Meet, Zoom bahkan hingga ke aplikasi sosial media seperti Whatsapp.

Aplikasi Whatsapp mempunyai fitur yang lengkap, cepat, mudah mengoperasikan, dan praktis hanya dengan menggunakan handphone. Aplikasi Whatsapp memiliki banyak fitur obrolan. Salah satu fitur tersebut adalah obrolan grup atau group chat. Fitur tersebut memungkinkan pengguna Whatsapp mengobrol dalam sebuah ruang obrolan yang biasa disebut sebagai grup. Jumlah maksimal anggota 250 pengguna. Obrolan grup dalam layanan Whatsapp dapat dibuat tanpa syarat, dan pembuat grup dapat menambahkan anggota hingga mencapai batas maksimal (Utomo dan Ubaidillah: 2018).

Guru sebagai fasilitator dalam mentransfer ilmu pengetahuan kepada siswa memerlukan media dan model pembelajaran yang memungkinkan mudah dalam menguasai materi. Media pembelajaran merupakan alat bantu yang digunakan pada saat prose pembelajaran. Model pembelajaran merupakan konsep cara belajar mengajar untuk mencapai tujuan pembelajaran yang tercermin dari hasil belajar yang dicapai. Jika guru salah memilih media dan model pembelajaran, maka akan berdampak pada hasil belajar (Utomo dan Ubaidillah: 2018).

Aplikasi Whatsapp ini dapat digunakan sebagi media pembelajaran sesuai dengan kebutuhan dan kesepakatan dari guru dan siswanya, dan bisa dilakukan dengan membuat satu grup tertentu yang tergabung antara siswa dan gurunya. Menurut Buss (2012) dalam Kartika dan Pratama (2017), Whatsapp sebagai M-Learing mampu menciptakan suasana akademis yang kondusif karena dapat digunakan diamanapun dan kapanpun. Implementasinya dalam pembelajaran mampu menghadirkan suasana belajar yang santai, sehingga menciptakan 
kedekatan emosional.

Melalui fitur grup pada aplikasi Whatsapp, guru dan siswa dapat melakukan kegiatan diskusi. Biasanya guru memberikan materi pembelajaran dan memberi kesempatan siswa untuk bertanya. Namun, diskusi yang dilakukan ini bersifat monoton dan hanya sebagian siswa yang aktif. Agar diskusi tidak bersifat monoton strategi Giving Question and Getting Answer adalah model pembelajaran berbasis masalah yang biasanya diterapkan dipembelajaran dikelas langsung atau tatap muka, maka kali ini strategi Giving Question and Getting Answer akan diterapkan pada pembelajaran diskusi menggunakan aplikasi Whatsapp pada materi genetik. Kelebihan khususnya dapat meningkatakan sikap kritis menemukan masalah dan kemampuan siswa mengemukakan pendapat.

Seperti yang dikemukan oleh Surpijono (2009:110) dalam Nopriana, dkk., (2015) bahwa kelebihan dari penggunaan model pembelajaran GQGA (Giving Question and Getting Answer) yaitu (a) Suasana belajar jadi lebih aktif, (b) Siswa dapat kesempatan baik secara individu maupun kelompok untuk menanyakan hal-hal yang belum dimengerti, (c) Guru dapat mengetahui penguasaan anak terhadap materi yang disampaikan, dan (d) Mendorong siswa untuk berani mengajukan pendapatnya.

Pembelajaran pada kelas yang dilakukan menggunakan aplikasi Whatsapp langkahlangkah yang diterapkan dengan menggunakan bantuan strategi pembelajaran strategi Giving Question and Getting Answer pada kelas 6E microteaching yaitu online learning untuk satu kali pertemuan pada materi genetik. Sebelum memulai pembelajaran mahasiswa yang berperan sebagai guru membuka pembelajaran dengan mengucapkan salam terlebih dahulu dan memperkenalkan diri. Kemudian mengecek kehadiran siswa lalu menyampaikan tujuan pembelajaran. Setelah membuka pemebalajaran kemudian guru menyampaikan materinya dengan menggunakan strategi Giving Question and Getting Answer (Gambar 1 dan 2)

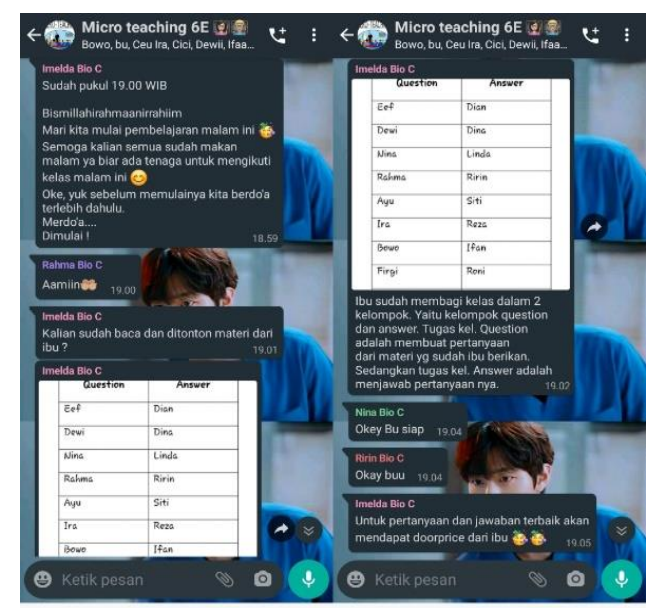

Gambar 1. Kegiatan Pembukaan pada Pembelajaran Biologi Via WhatsApp 


\section{dengan Strategi Giving Question and Getting Answer .}

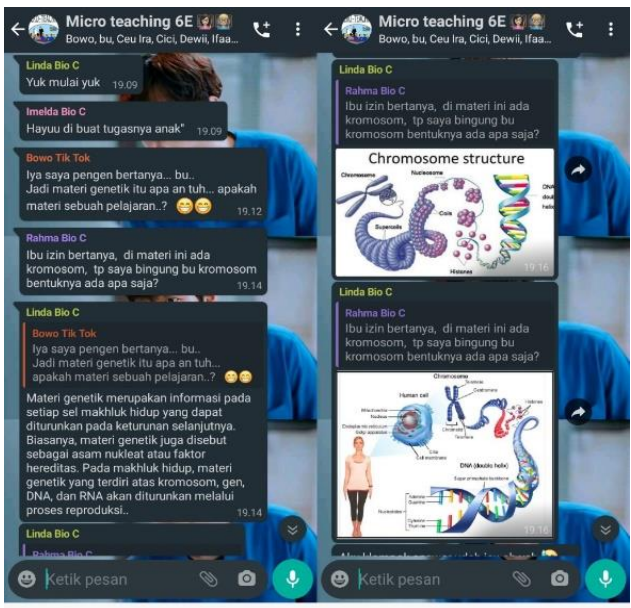

\section{Gambar 2. Kegiatan Inti pada Pembelajaran Biologi Via WhatsApp dengan Strategi Giving Question and Getting Answer.}

Strategi Giving Question and Getting Answer dapat memberikan pelajaran yang lebih menyenangkan dari pada pembelajaran sebelumnya yang tidak menggunakan strategi pembelajaran dan cenderung monoton karena guru cenderung lebih banyak memberikan materi pembelajaran yang khawatir tidak dipahami oleh siswa. Hal ini sesuai dengan definisi pembelajaran aktif yang dipaparkan dalam penelitian yang ditulis oleh Zaini (2008) yaitu pembelajaran yang melibatkan siswa secara aktif, dengan tujuan agar siswa memiliki jiwa kemandirian dalam belajar. Kemandirian siswa pada Pembalajaran Daring dengan menggunakan strategi Giving Question and Getting Answer yang diterapkan pada Whatsapp dapat dilihat pada sikap kritis menemukan masalah dan kemampuan siswa mengemukakan pendapat.

Penerapan model pembelajaran GQGA (Giving Question and Getting Answer) dalam kegiatan pembelajaran daring biologi menjadi lebih menyenangkan bagi siswa sehingga siswa lebih aktif dalam kegiatan pembelajaran daring biologi yang berlangsung. Siswa lebih leluasa mengeluarkan pendapatnya baik itu berupa pertanyaan yang berisi tentang ketidak pahaman terhadap materi ataupun jawaban yang melatih siswa untuk berani mengeluarkan pendapat dan menumbuhkan rasa percaya diri siswa terhadap kemampuannya sendiri.

Menurut Wiliwida (2013) melalui pembelajaran aktif siswa memiliki kemapuan mengingat yang lebih besar dibanding dengan pembelajaran pasif, sehingga penguasaan siswa terhadap materi menjadi lebih baik, yang secara tidak langsung dapat meningkatkan hasil belajar siswa. Selain itu, menurut Avana (2018) strategi Giving Question and Getting Answer memberikan pengaruh terhadap hasil belajar siswa yang terlihat pada pemahaman siswa 
terhadap materi yang diajarkan. Sehingga strategi Giving Question and Getting Answer yang diterapkan pada Whatsapp menjadi salah satu cara alternatif yang dapat digunakan pada Pembalajaran Daring sehingga proses pembelajaran tidak cenderung bersifat pasif dan monoton.

Hal ini didukung hasil penelitian Chasanah, dkk., (2012) yang menyatakan bahwa penggunaan strategi Giving Question and Getting Answer terbukti efektif dapat diterapkan dalam Pembalajaran daring menggunakan Whatsapp dalam meningkatkan sikap kritis dalam memecahkan masalah. Siswa bekerja berdasarkan langkah-langkah pembelajaran yang sudah disetting dan melakukan kegiatan sesuai yang di intruksikan oleh guru guna memecahkan masalah. Model pembelajaran ini membuat siswa menjadi sangat aktif dalam mengemukakan pendapat dan memecahkan masalah yang dibutuhkan guna mendukung konsep yang dipelajari.

\section{KESIMPULAN DAN SARAN}

\section{Kesimpulan}

Berdasarkan hasil penelitian yang dilakukan, maka dapat disimpulkan bahwa penggunaan Strategi Giving Question and Getting Answer berpengaruh terhadap pembelajaran daring biologi via Whatsapp. Pembelajaran daring menggunakan aplikasi Whatsapp dengan strategi Giving Answer and Getting Question dapat memberikan pembelajaran yang lebih menyenangkan sehingga meningkatkan antusias dan keaktifan siswa. Sehingga, penggunaan strategi Giving Question and Getting Answer bisa menjadi alternatif dalam pembelajaran daring biologi via Whatsapp pada kondisi yang tidak memungkinkan untuk dilakukannya pembelajaran tatap muka.

\section{Saran}

Saran yang diberikan untuk peneliti lain yaitu penggunaan strategi Giving Question and Getting Answer pada pembelajaran daring biologi via Whatsapp bisa menjadi alternatif dalam pembelajaran daring biologi via Whatsapp pada kondisi yang tidak memungkinkan untuk dilakukannya pembelajaran tatap muka. Hanya saja perlu diperhatikan lagi apakah siswa dan siswi memiliki sinyal yang baik untuk melakukan pembelajaran kelas online dan penelitian ini dapat dijadikan bahan kajian oleh peneliti lainnya. Peneliti lain juga dapat meneliti pengaruh strategi lainnya pada pembelajaran daring via Whatsapp.

\section{DAFTAR RUJUKAN}

Avana, Nurlev. "Pengaruh Pembelajaran Aktif Tipe Giving Question and Getting Answer 
Terhadap Pemahaman Konsep Mahasisswa Pada Pembelajaran Statistik”. Jurnal Tunas Pendidikan (1), no. 1 (2018), 91-100.

Chasanah, dkk. "Pengaruh Penerapan Model Pembelajaran Giving Questions And Getting Answer Terhadap Hasil Belajar Siswa Kelas X SMA Negeri Banyudono Tahun Ajaran 2011/2012”. Pendidikan Biologi 4, no. 3 (2012), 29-38.

Kartika dan Pratama. "Pengaruh Penggunaan Whatsapp Messenger Sebagai Mobile Learning Terintegrasi Metode Group Investigation Terhadap Kemampuan Berpikir Kritis". Jupiter : Jurnal Pendidikan Teknik Elektro (2), no. 2 (2017), 33-38.

Nengsi dan Oktaria. "Pengaruh Model Pembelajaran GQGA (Giving Questionand Getting Answer) Terhadap Hasil Belajar Siswa”. Bioedusains: Jurnal Pendidikan Biologi dan Sains 3, no. 3 (2019), 111-121.

Nopriana, dkk. "Pengaruh Model Giving Question And Getting Answer (GQGA) Terhadap Hasil Belajar IPA Terpadu Siswa Kelas VII SMP Negeri Sumberharta”. Jurnal Inkuiri 1, no. 1 (2015), 50-65.

Sahidillah dan Miftahurrisqi. "Whatsapp Sebagai Media Literasi Digital Siswa". Varia Pendidikan 31, No. 1 (2019), 52-57.

Utomo dan Ubaidillah. "Pemanfaatan Aplikasi Whatsapp pada pembelajaran Berbasis Masalah untuk Mata Kuliah Akuntansi Internasional di Universitas PGRI Madiun”. Jurnal Teknologi Pendidikan 6, no. 2 (2018), 119-211.

Warsita, Bambang. 2008. Teknologi Pembelajaran Landasan \& Aplikasinya. Jakarta: Rineka Cipta.

Wiliwida, Ning. 'Kefektifan Strategi Giving Question And Getting Answer Terhadap Hasil Belajar Sumber Daya Alam Siswa Kelas IV Sekolah Dasar 06 Petarukan Pemalang'. Skripsi. Universitas Negeri Semarang. 2013.

Zaini, H., dkk. 2008. Strategi Pembelajaran Aktif. Yogyakarta. Pustaka Insan Madani. Komputindo. 